\begin{tabular}{|r|}
\hline Article Progress Time Stamps \\
Article Type: Research Article \\
Manuscript Received: $7^{\text {th }}$ Oct. 2018 \\
Review Type: Blind \\
Final Acceptance:: $29^{\text {th }}$ Nov, 2018 \\
DOI Prefix: 10.22624 \\
\hline
\end{tabular}

\title{
Evaluation of Automated Metering With Flexible Management and Monitoring System
}

\author{
${ }^{1}$ Edemirukaye Ukeh Orodje and ${ }^{2}$ Apeh Simon T. \\ Department of Computer Engineering \\ University of Benin \\ P.M.B 1154, Benin City, Nigeria \\ E-mail: 'edemirukaye.orodje@eng.uniben.edu;'apeh@uniben.edu \\ Phone: +2348164633759
}

\begin{abstract}
There are several electrical power losses affecting economy of the power Distribution Company. In developing country like Nigeria the percentage of Non-technical losses has been quite high affecting the availability of electrical power supply in the country. One of the biggest challenges facing us today is caused by increase in energy consumption and how we can make consumers aware of their electricity usage and provide them with options to manage usage and reduce waste. The present method is based on manual monitoring and poor power management. We hereby present "Evaluation of an automated metering with flexible management and monitoring system called "ATMWFM" system for effective monitoring of electrical power parameters and energy consumed by appliances at different loading conditions and period of the day. This paper describes the preliminary development on design methodology of the ATMWFM through a wireless transceiver, flexible Home energy planner and web-based system. When the ATMWFM system is fully implemented it would perform proper power management, adequate communication (on consumers mobile phone), and effective monitoring and control option. All meters being monitored and readings recorded automatically on centralized wireless based system, it would reduce chance of human errors. It will make consumers more aware of their electricity usage plan and still monitor the meter remotely. It will eliminate nonpayment of electricity bills; electricity theft saving huge amount of time and money.
\end{abstract}

Keywords: Electrical power, automated energy metering system, Home energy planner (HEP), Web-based system and Wireless Systems

\section{BACKGROUND TO THE STUDY}

Power authority is saddled with the responsibility of generation, transmission and distribution of electricity to ensure that power is available to electricity consumers. Our focus is on a section of Low Voltage power distribution network (Olugbenga et al, 2013). The availability of Constant electrical power supply is one of the driving forces behind the development of any country (Apeh S.T and Mokogwu C.N, 2013). 
In spite of the billions of naira invested by the federal government on prepaid meters some customers today don't have meters Some residential areas enjoy power supply while others do not, Consumers are not aware of their consumptions and no way to manage consumptions while using existing appliances. When giving power to some part of the town, the power authority is not reflecting on the wastage by electricity consumers when during the day security lights bulbs will be on not using but wasting power (Anvari- Moghddam et al, 2015). There is no serious monitoring and feedback on the power distribution network for electricity consumers. The rate of non-technical losses in developing countries like Nigeria is quite high which ranges from electricity theft to non-payment of electricity bills.

To overcome these disadvantages and to complement the efforts of power management initiative under way in various countries a research paper title "evaluation of an automated metering, with flexible management and monitoring (ATMWFM) system which can be implemented in Nigeria is hereby proposed.

In this proposed system, the pre-paid energy meters will have proper power management, adequate communication, and effective monitoring and control option. If the amount falls below a certain minimum amount, then a message will be sent to the consumer on mobile phone. With all meters being monitored and the meter readings recorded automatically on centralized wireless monitoring system. There will be no chance of human errors. It will make consumers more aware of their electricity usage saving huge amount of time and economically viable. The authors wish to emphasize that some basic calculation and results of the ATMWFM system are not present in this paper but will be published elsewhere. This paper only reports on the preliminary development towards the design and evaluation of ATMWFM system.

\section{RESEARCH STATEMENT}

Poor power management and uneven load shedding, Inappropriate Monitoring on the electricity consumption, Ineffectiveness of revenue collection from consumers by power distribution staff, Inadequate communication between the Electricity provider and customers, Inflexible Customer power consumption planner and Creation of an effective standby power detection on the appliances measured.

\subsection{Objective}

The aim of this research is to design and evaluate an automated Metering, Power Management and Monitoring System with the following objectives:

i. To design an automated Electrical power metering system

ii. To design an intrusion detection and tamper-proof system.

iii. To design web-based system for power management and monitoring (which includes fraud and fault detection system).

iv. Design a flexible Home energy Planner

v. To design a load dependent and load shedding

vi. Evaluation of the system

\subsection{Relevance Of The Study}

A new system where all meters can be monitored on centralized wireless based system with proper power management. Modern technologies to monitor reliability of power supply on the electricity consumption. 


\section{RELATED WORKS}

Fabiano Salvadori et al (2015) carried out Monitoring in Industrial Systems Using Wireless Sensor Network with the use of intelligent Sensors Modules (ISMs) and the Remote Data Acquisition Units (RDAUs). The objective was achieved. Nguyen et al, (2013) Energy intelligent Buildings based on User Activity. They summarized and compare several studies on building energy and comfort management (BECM) systems, where simulation results show up to $58 \%$ savings on energy for lighting and $10-40 \%$ for HVAC system.

Apeh S. T. and Mokogwu C.N (2013) developed a home power management system. The PIC16F887 Microcontroller was programmed to provide 24 hour real-time timing power consumption management according to user-supplied timing parameters made available to the programmed Code with the help of the PCF8583 real time clock. The home power management system developed under test produced outputs which exhibited good correlation with the input supply. Whereas the input to the device was $186 \mathrm{~V}$, the output for ports $1,2,3,4$ and 5 were respectively $187 \mathrm{~V}, 185 \mathrm{~V}, 184 \mathrm{~V}, 185 \mathrm{~V}$ and $183 \mathrm{~V}$ which is a satisfactory input-output correlation. The unit also exhibited good implementation of the timing algorithm for all programmed outputs. It switched "ON" and "OFF" at the set times for the regulated ports showing that power was managed as desired in accordance with the inputted timing parameters. This flexibility in an automation system is one strong point of this device.

\section{RESEARCH METHODOLOGY}

\subsection{The Research Design}

The research objective was accomplished through the process described in figure 4.1 the design workflow is broken down into stages each consists of activities that would be carried out iteratively as shown in the flow diagram in figure 4.1 until the final desired outcome will be achieved. The first stage specifies comprehensive analysis of the billing problem follow by material selection and proposed design techniques which includes designing the prepaid meters with inbuilt wireless transceiver as shown in figure 4.5, designing the home energy planner as shown in figure 4.8, creating a database for billing and historian, designing fault reporting, fraud and fault detection system, webbased system (see use-case diagram shown in figure 4.5) for system monitoring and power management that will be used to achieve the research objectives. Thereafter proceed to integration and simulation of the complete system for evaluation process then live comparison of the energy consumption in KWH, billing and reports generated on a centralized wireless monitoring station. 


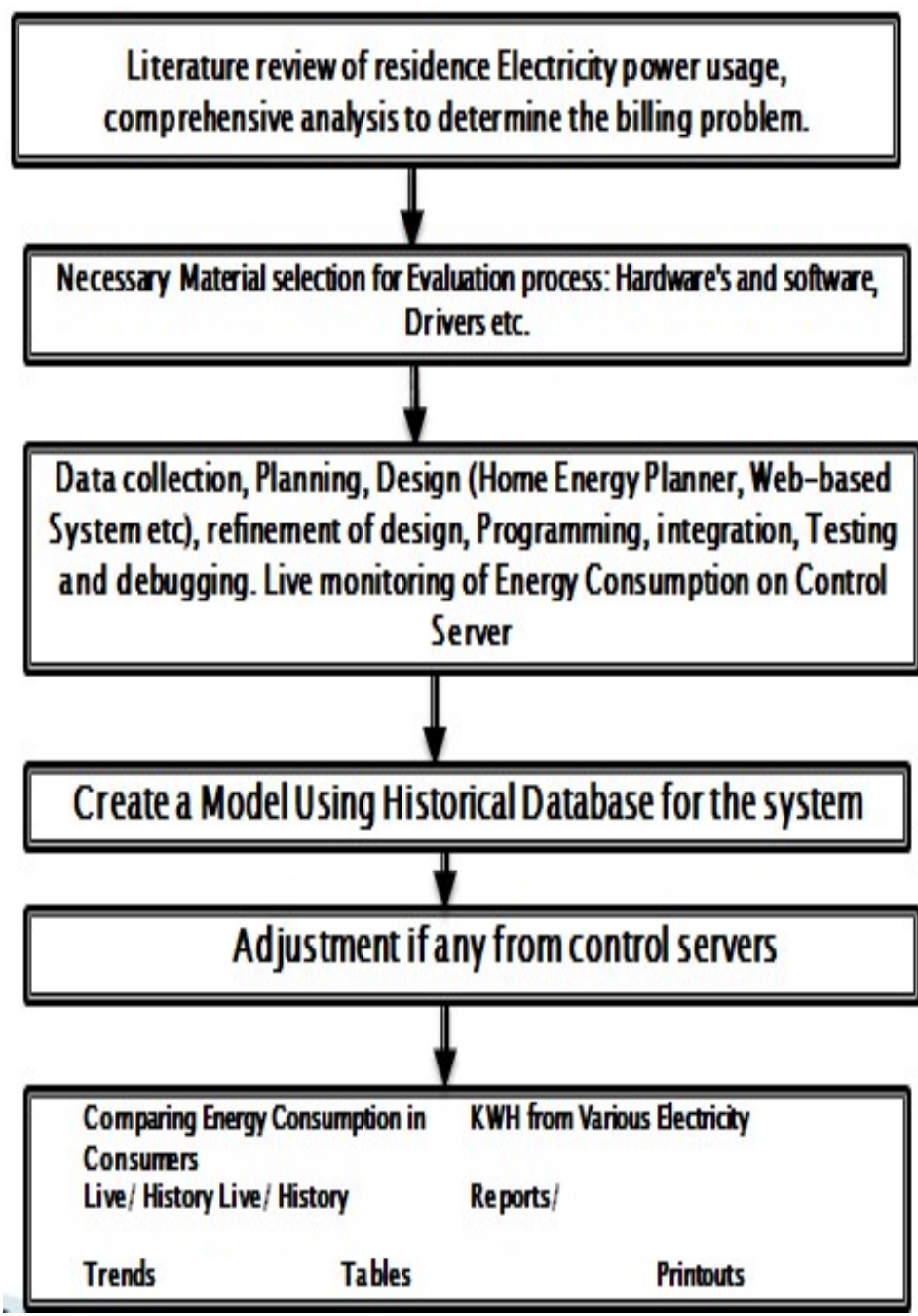

Figure 4.1: Flow diagram showing the design methodology

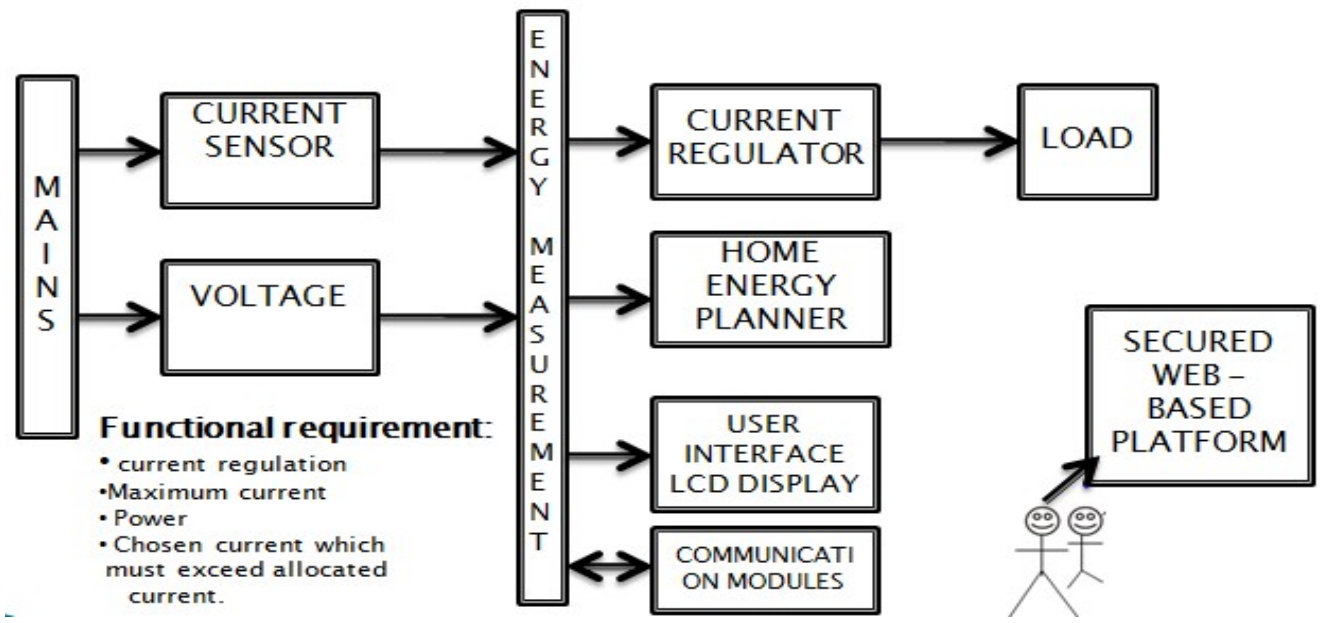

Figure 4.2 Block diagram of the end-user automated metering power management and monitoring system 


\subsection{Design of end-user ATMWFM system}

This stage of design is concern with the materials and methods for the hardware of the end-user system. The activities include the selection of current sensor that will sense the amount current drawn by consumer load, potential transformer that will measure the amount voltage across the entire circuit and the metering integrated circuit (IC). In the proposed metering IC design, analog to digital signal conversion would be carried out, phase correction and multiplication of current and voltage is performed by energy metering IC. This IC which will measure the power consume then convert it to frequency for the microcontroller to read (see figure 4.2 and 4.5) before reporting through the wireless transceiver ( LoraWAN) to transmit information at a distance of $100 \mathrm{~km}$ to the monitoring station.

\subsubsection{The Current sense unit}

The current sense unit is designed to sense the amount of current flowing along the supply line. It consists of a current transformer connected in series with the load and a voltage attenuation network (see figure $4.4 \mathrm{a}$ and figure $4.4 \mathrm{~b}$ ).

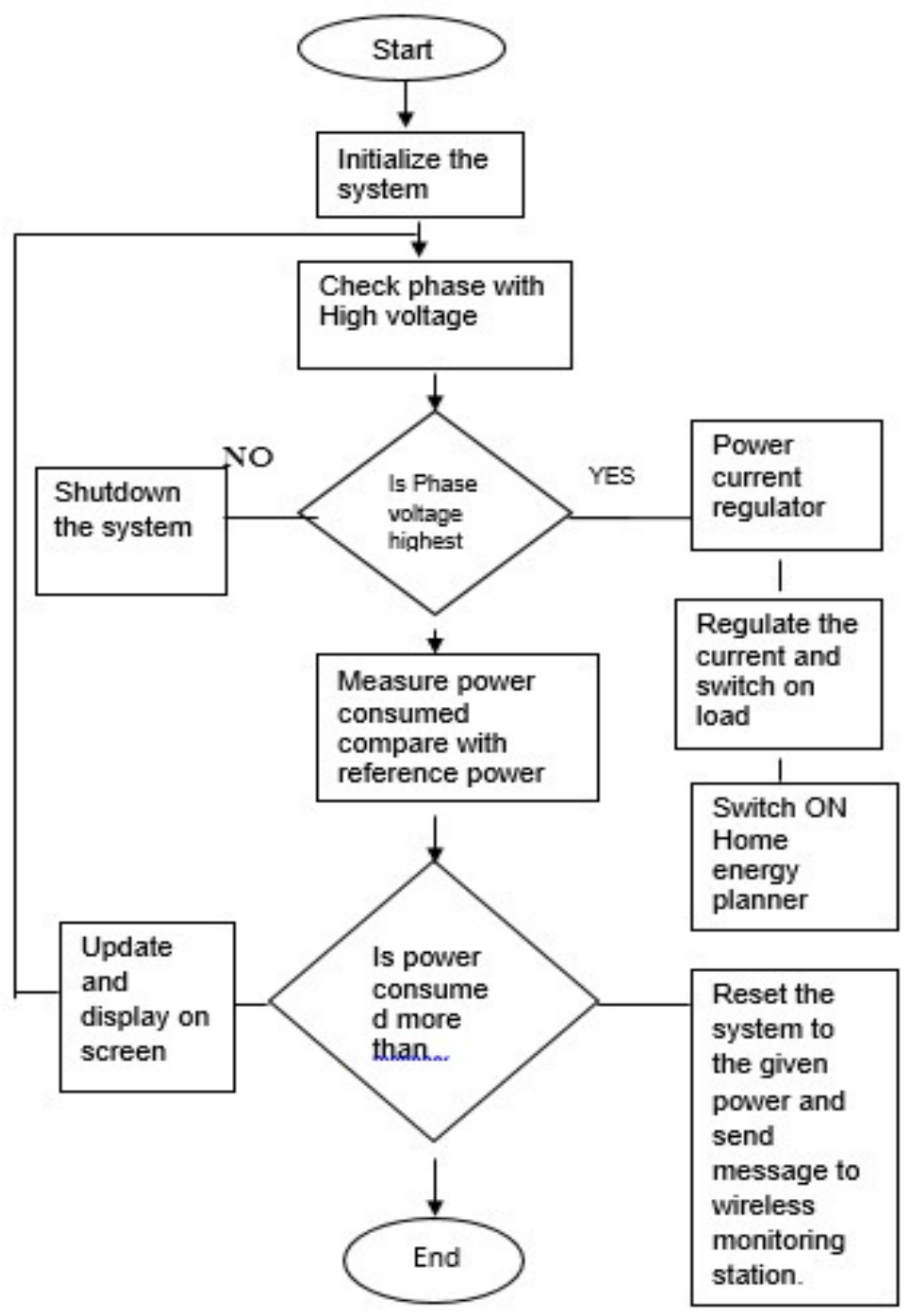

Figure 4.3: Flow diagram of power management of the end-user 


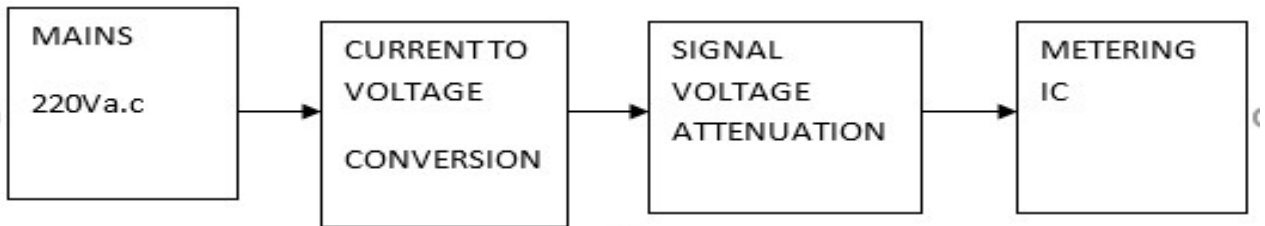

Figure 4.4a: Block diagram of the current sense unit

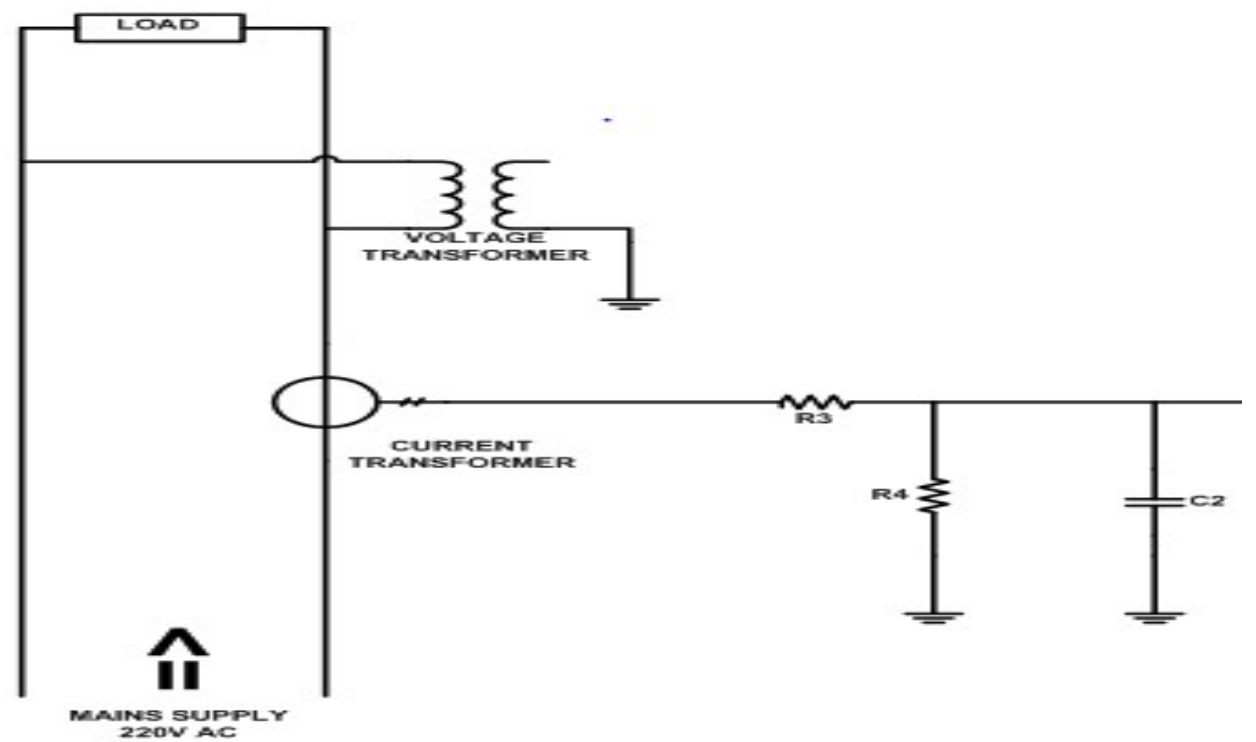

Figure 4.4b: Circuit diagram of current sense unit

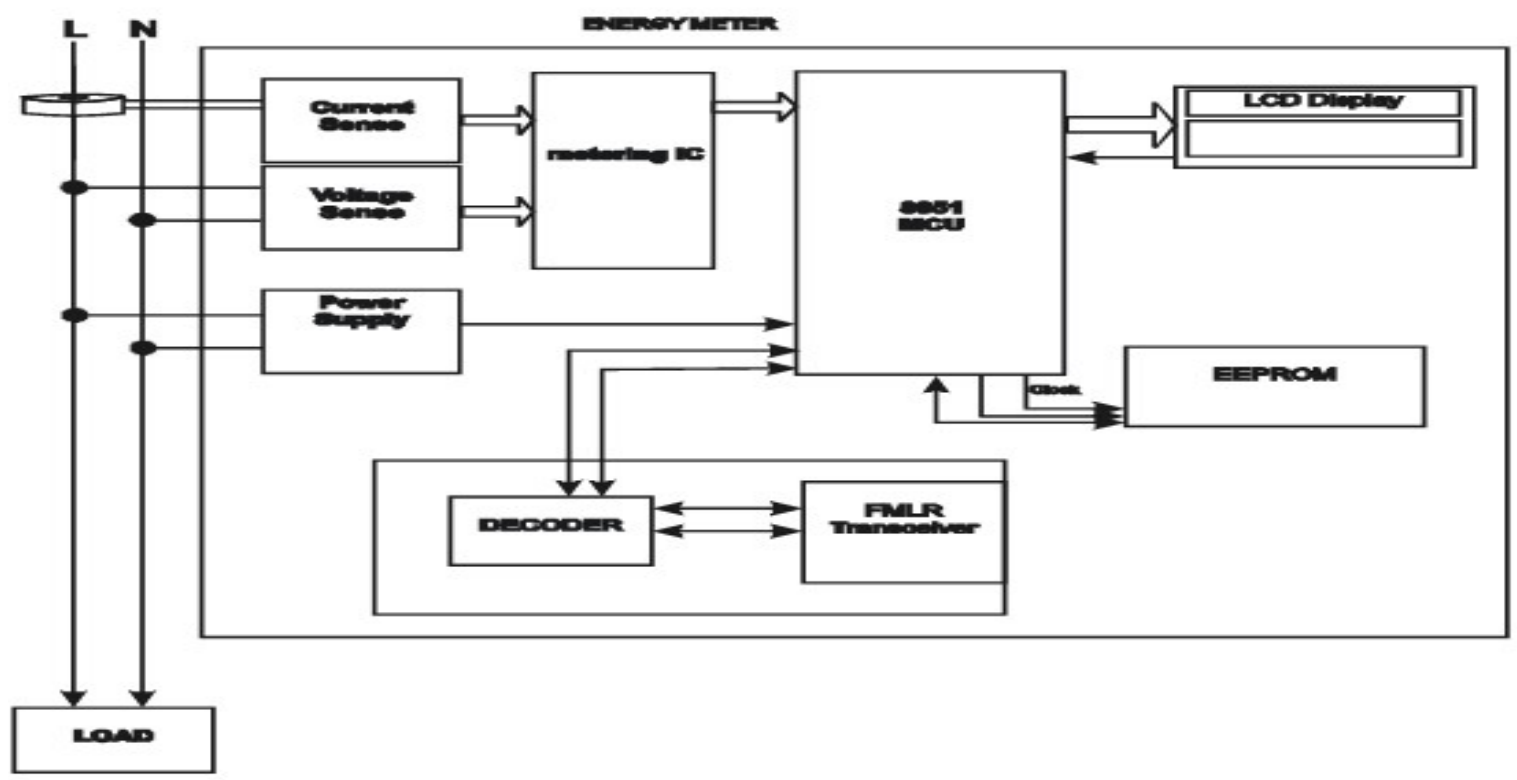

Figure 4.5: Diagram of the end-user section 
The proposed real power calculation method also holds true for nonsinusoidal current and voltage waveforms.

Using the Fourier Transform, instantaneous voltage and current waveforms can be expressed in terms of their harmonic content.

$v(t)=V_{0}+\sqrt{2} \times \sum_{h \neq 0}^{\infty} v_{h} \times \sin \left(h \omega t+\propto_{h} \ldots \ldots \ldots \ldots \ldots . . .(1)\right.$

Where:

$V_{(\omega)}=$ the instantaneous voltage, $V_{o}=$ the average value, $V_{h}=$ the rms value of voltage harmonic and $h=$ phase angle of the voltage harmonic (Merabet L et al, 2013).

$i(t)=i_{0}+\sqrt{2} \times \sum_{h \neq 0}^{\infty} I_{h} \times \sin \left(h \omega t+\beta_{h}\right.$

Where:

$I_{(i)}=$ the instantaneous current, $I_{o}=$ the dc component., $I_{h}=$ the rms value of current harmonic, $h=$ the phase angle of the current harmonic (Merabet $\mathrm{L}$ et al, 2013).

\subsection{Monitoring station and web-based system}

The monitoring station and web-based system are mostly software with written programme and design interface in computer laptops. The software selection would based on some numbers of factors which include availability of design artifacts, availability of source codes, licenses, programming language, popularity, industry types, diversity of sizes of the systems, user-base, platforms and webtechnologies used and diversity of functionality provided. Preference would be given to web-based systems whose source code is readily available without license limitations.

\subsubsection{Proposed design consideration for the web-based technologies}

In the area of the web -technologies, the use of scripting programming language is proposed for both front end and back end design such as HTML, CSS, PHP, MYSQL, JAVA SCRIPT and SUBLIME TEXT. As part of the website design the proposed use-case diagram for the web-based system is shown in figure 4.7 . 


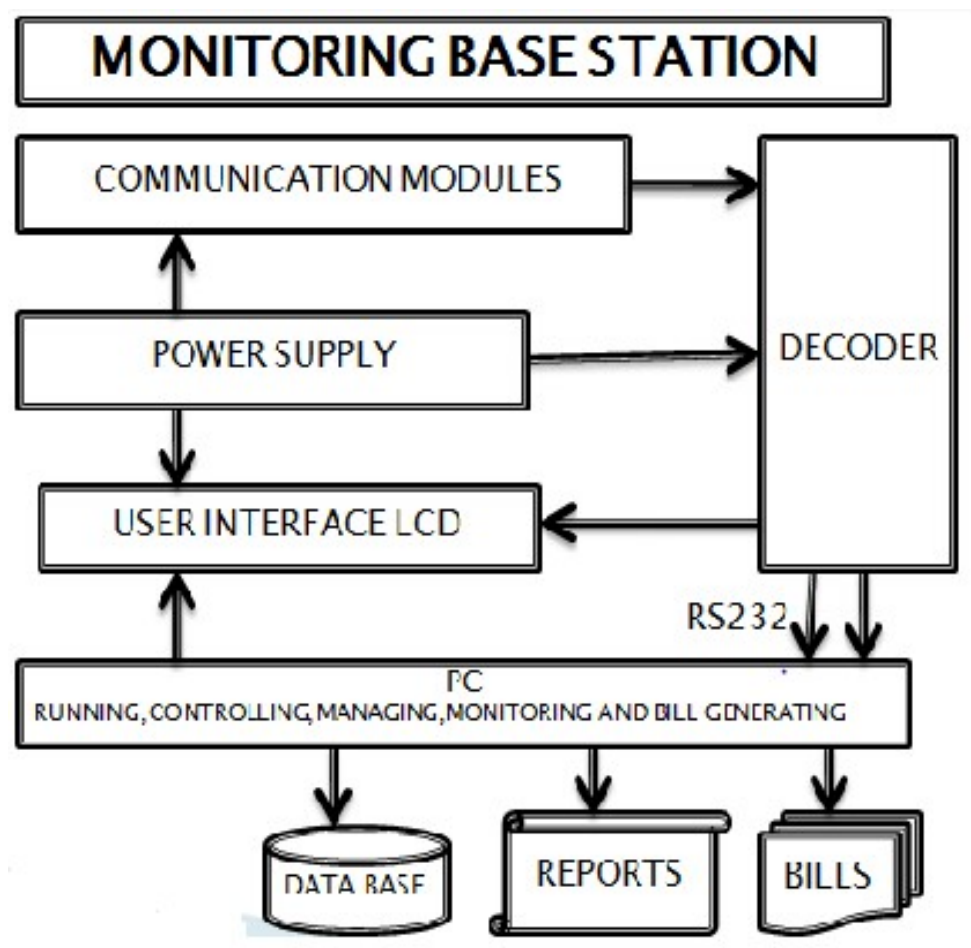

Fig 4.6 Block diagram of the Monitoring station 


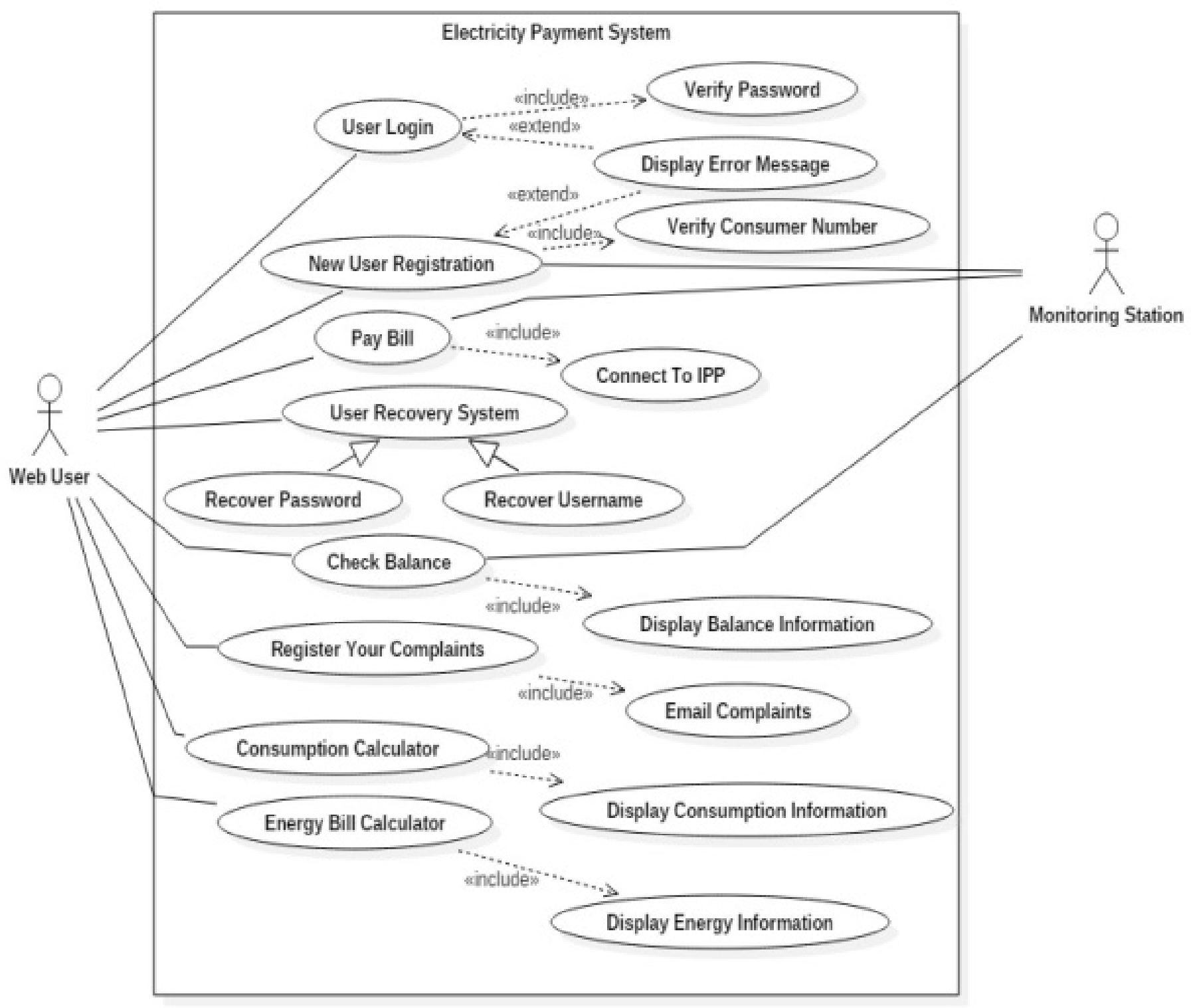

Figure 4.7 Use-Case diagrams for the Web-Based System 


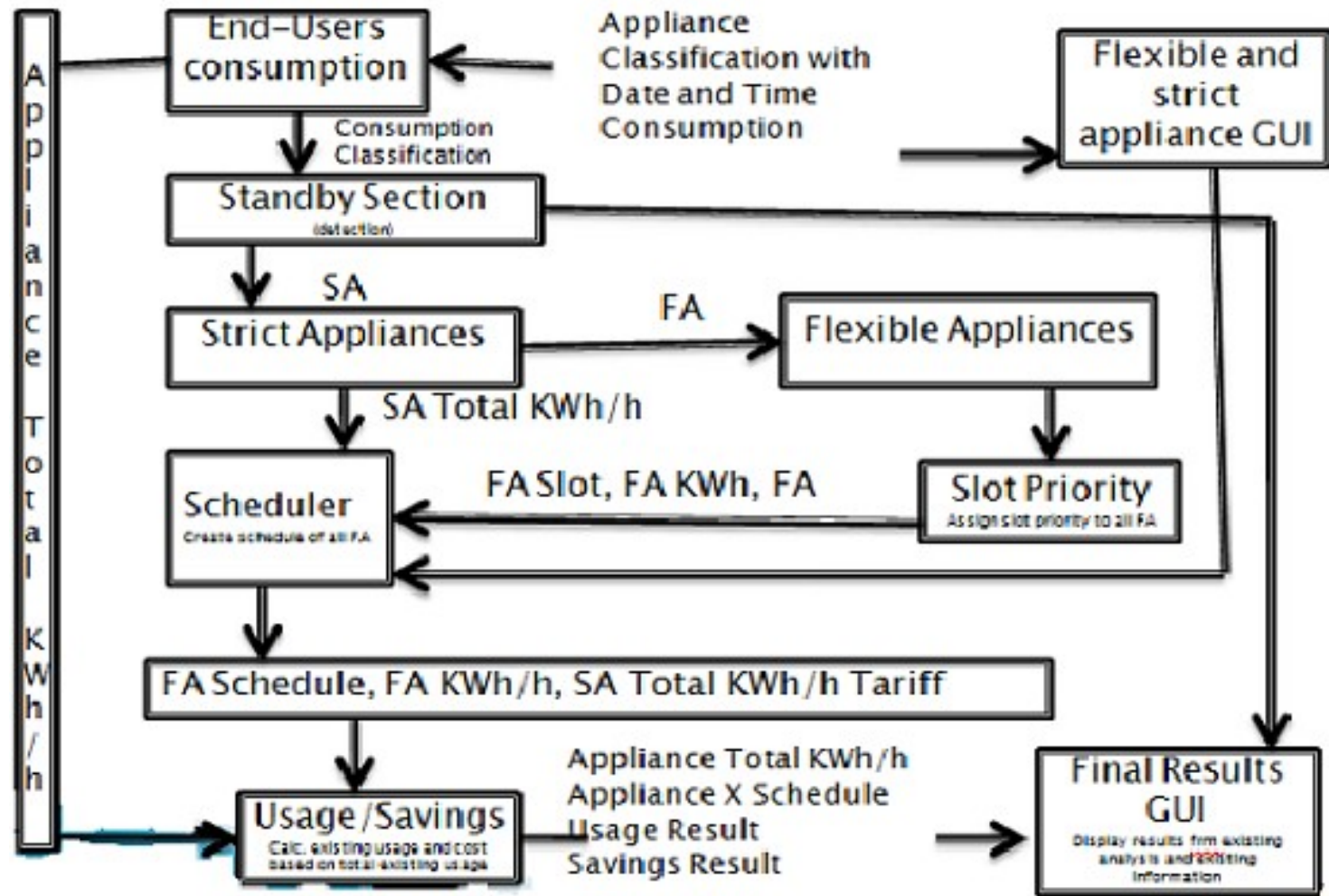

Figure 4.8 Flow diagram of Home energy planner

4.4 Design consideration for the Home Energy Planner

The design of the home energy planner would be carried out by JAVA SCRIPT as shown in figure 4.8 each block is a JAVA component where the end-users consumption component reads consumption of data from Appliance Graphical Users interface (GUI), in the appliance GUI that is where end-user classified their appliances as flexible or Strict Appliance. Here Flexible appliances are those appliances consumers place on schedule like washing machine, dish washers while strict appliances are those appliances end-user does not want to be given schedule because they need to run all the time such as refrigerators, entertainment devices etc.

Whereas the slot priority is a component that would assign slot priority to flexible appliances based on highest KWh needed and the amount of hours needed to run one session of an appliance I ascending order which data would be received from the flexible appliance component thereafter final results of all would be display at Final result GUI. As part of the design for the Home energy planner, the following stages is also proposed: Determine standby power consumption for all end-user appliances, Removing standby power consumption from existing data readings for all appliances, then add up total strict appliances power consumptions, Determine the power , time to run each appliance their respective usage per session for flexible appliances, assign slot priorities to flexible appliances on their average power consumption per session with respect to their loading condition, determine schedules for all flexible appliances and calculate estimated savings in KWh and Naira cost. 


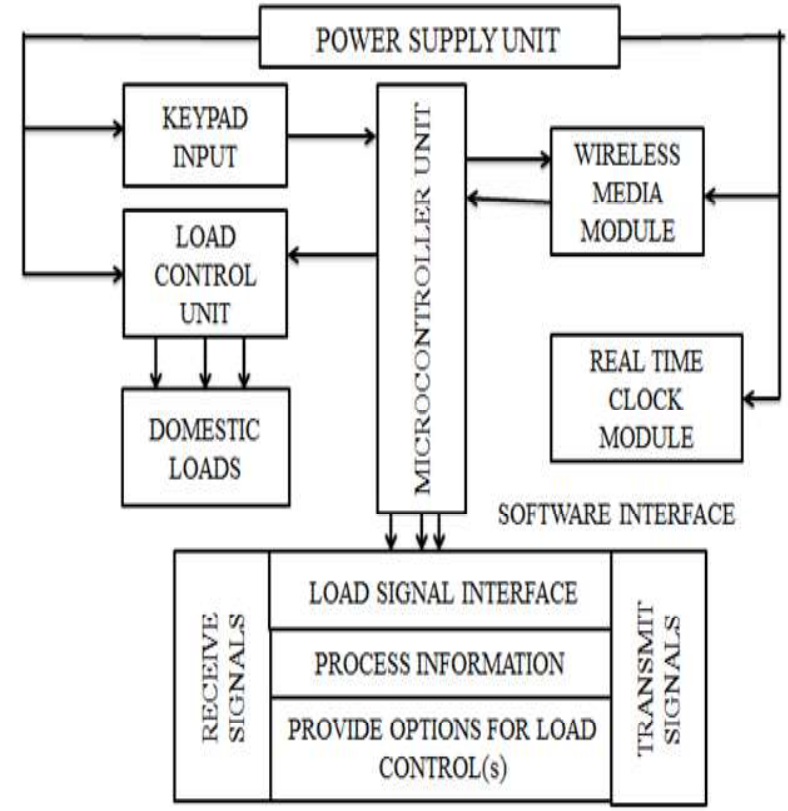

Figure 4.9a: Block diagram of interface of flexible Home energy planner

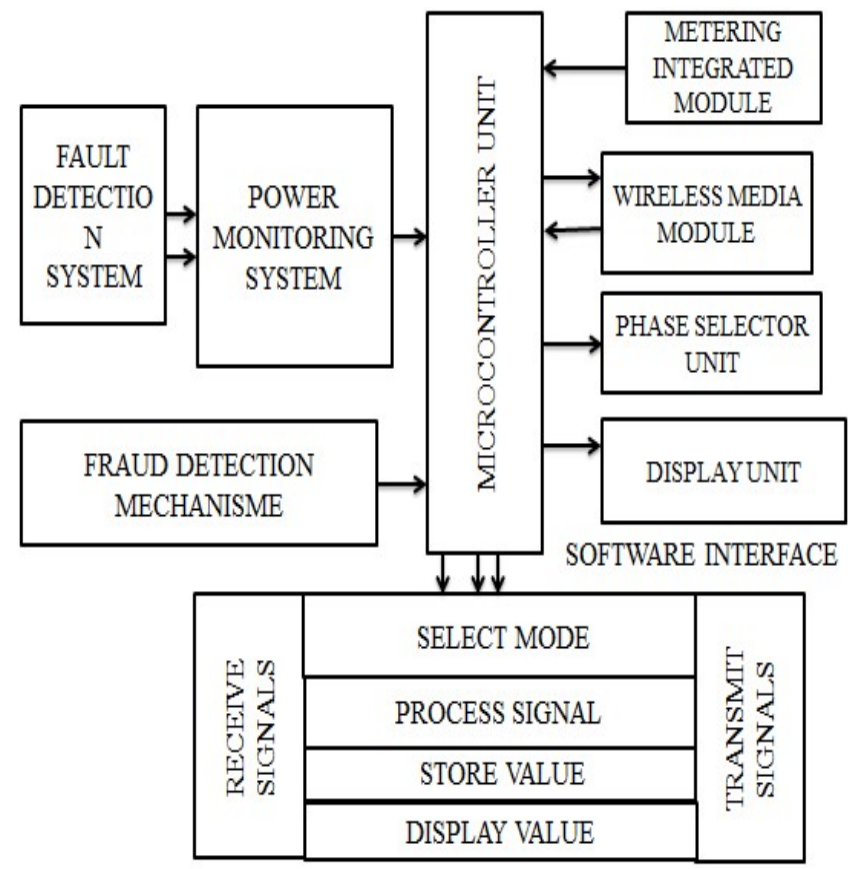

Figure 4.9b: Block diagram of interface of the metering system 
Fault detection system: this is the unit that the system uses to detect when a fault has occurred. The major fault that will be monitored is the phase failure faults. This circuit requires the connection of each of the phase to be monitored, into a sensor network with the error signal compared with a reference value. If the value deviates from the expected output, a fault is said to have occurred and the system will respond accordingly

Fraud detection: the system also has, incorporated with it, a fraud detection unit. The function of this unit is to notify personnel when or if the meter is opened. The opening can either be authorized or unauthorized. In terms of the authorized opening, a message will be transmitted to the power station but this message would be ignored since a scheduled maintenance operation has be documented to take place. However, when this opening is unauthorized, the message will receive attention by the relevant authorities due to the fact that the message will also contain a code that the power company can use to identify the exact meter that is being tampered.

Power monitoring system: the meter will have the ability of giving the user the opportunity to change to another power phase in the event that the current phase that the meter is using, fails. This unit is responsible for the monitoring of the availability or unavailability of phase power and send result to the microcontroller. The microcontroller is programmed to enable the user change power supply phase at will.

Metering integrated module: this is the main part of the system. The part that measures the value of power consumed by the load and sends the value to be processed, into the microcontroller. Wireless media module: the value of the power consumed sent wirelessly to the monitoring power station.

Also, the power authority has the ability to recharge the meter of the consumer as well as to carry other ability of the meter such as override shut down in case of defection of the rules. This communication with the system by the provider and the communication by the system is done wirelessly. This unit is responsible for the full duplex wireless communication between the system and the monitoring station.

Microcontroller unit: the full system and its operation will be carried out by an embedded system. An embedded system is an electronic circuit that has at least one programmable integrated circuit in it. For the complete operation of the system, the microcontroller is programmed with the required protocol to ensure that the system behaves satisfactorily as an advanced metering equipment.

Phase selector unit: the ability $f$ the meter to select a phase where power is present to power the house, is made possible by this unit. This is a static relay based phase selector system that will enable the meter to select and deploy one active phase.

Display unit: for the interaction between the user and the system, a graphical user interface is employed. This will be a screen that will enable the user to interact with the metering circuitry and also for the internal circuitry to display to the user, its current operations.

\section{Signal attenuation network}

In order to step down this voltage to $20 \mathrm{mV}$ max, we need to determine a suitable value of $\mathrm{R} 3$ in the circuit diagram of figure: 4.10 . 


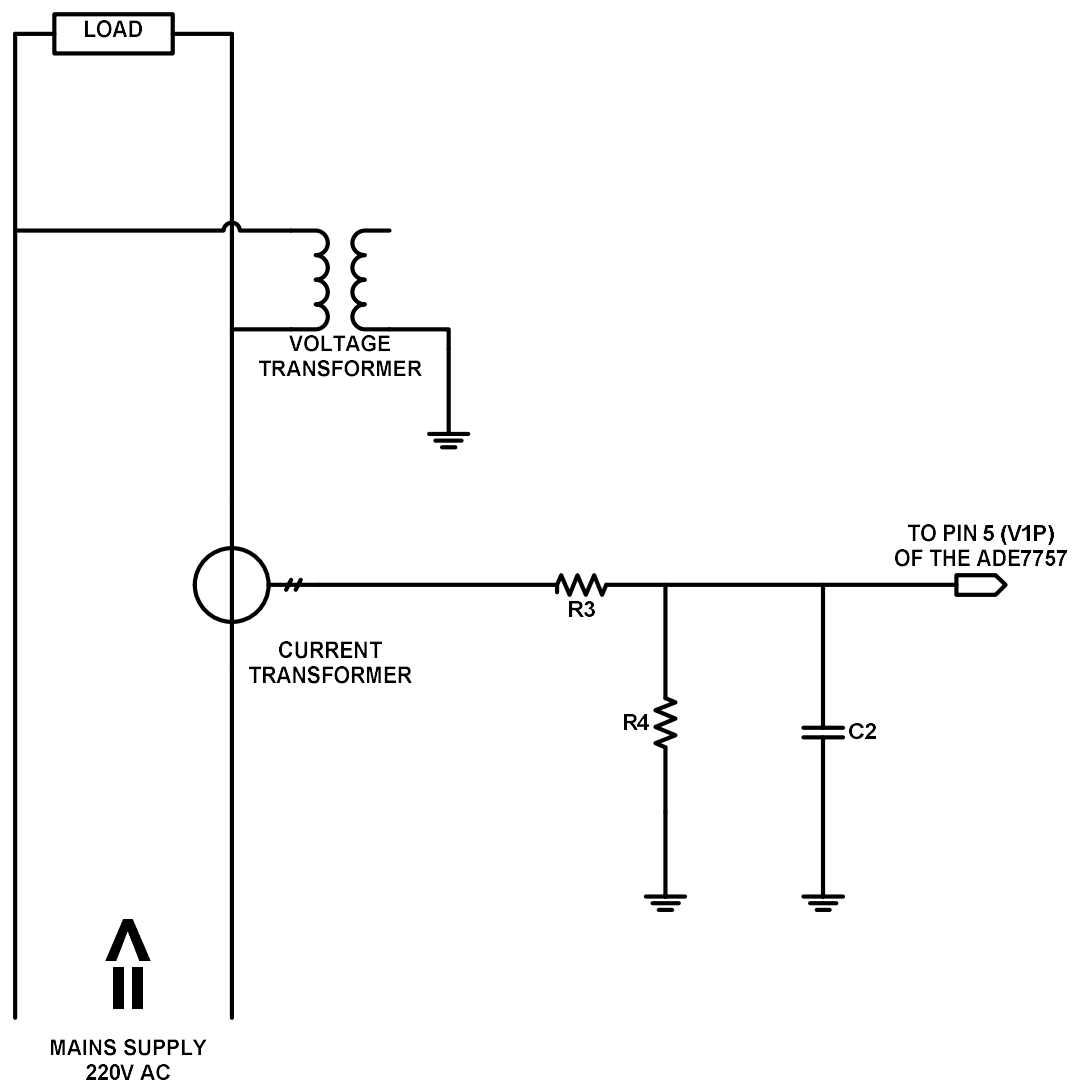

Figure 4.10: Circuit Diagram Of Current Sense Unit

$\mathrm{R} 4$ is chosen as $200 \Omega$ and $\mathrm{C} 2$ is chosen as $150 \mathrm{nF}$. This forms a low pass filter to prevent dangerous high frequency signals such as lightning or ESD from passing through the ADE7757 current channel. The maximum frequency is

Frequency $\mathrm{f}=1 /(2 \pi \times \mathrm{RC})$

$=1 /\left(2 \pi \times 200 \times 150 \times 10^{-9}\right)$

$=5.3 \mathrm{KHz}$

Signal Voltage input $\mathrm{V} 2=5.8 \mathrm{~V}$

Desired voltage output $\mathrm{V} 3$ across $\mathrm{R} 4=20 \mathrm{mV}$

Resistor R4 $=200 \Omega$

Resistor R3 =??

To obtain resistor $\mathrm{R} 3$, we apply the voltage divider rule

$\mathrm{V} 3=(\mathrm{V} 2 \times \mathrm{R} 4) /(\mathrm{R} 3+\mathrm{R} 4)$

$\mathrm{R} 3=[(\mathrm{V} 2 \times \mathrm{R} 4) / \mathrm{V} 3]-\mathrm{R} 4$

$=\left[(5.8 \times 200) / 20 E^{-3}\right]-200$

$=57800 \Omega$ 


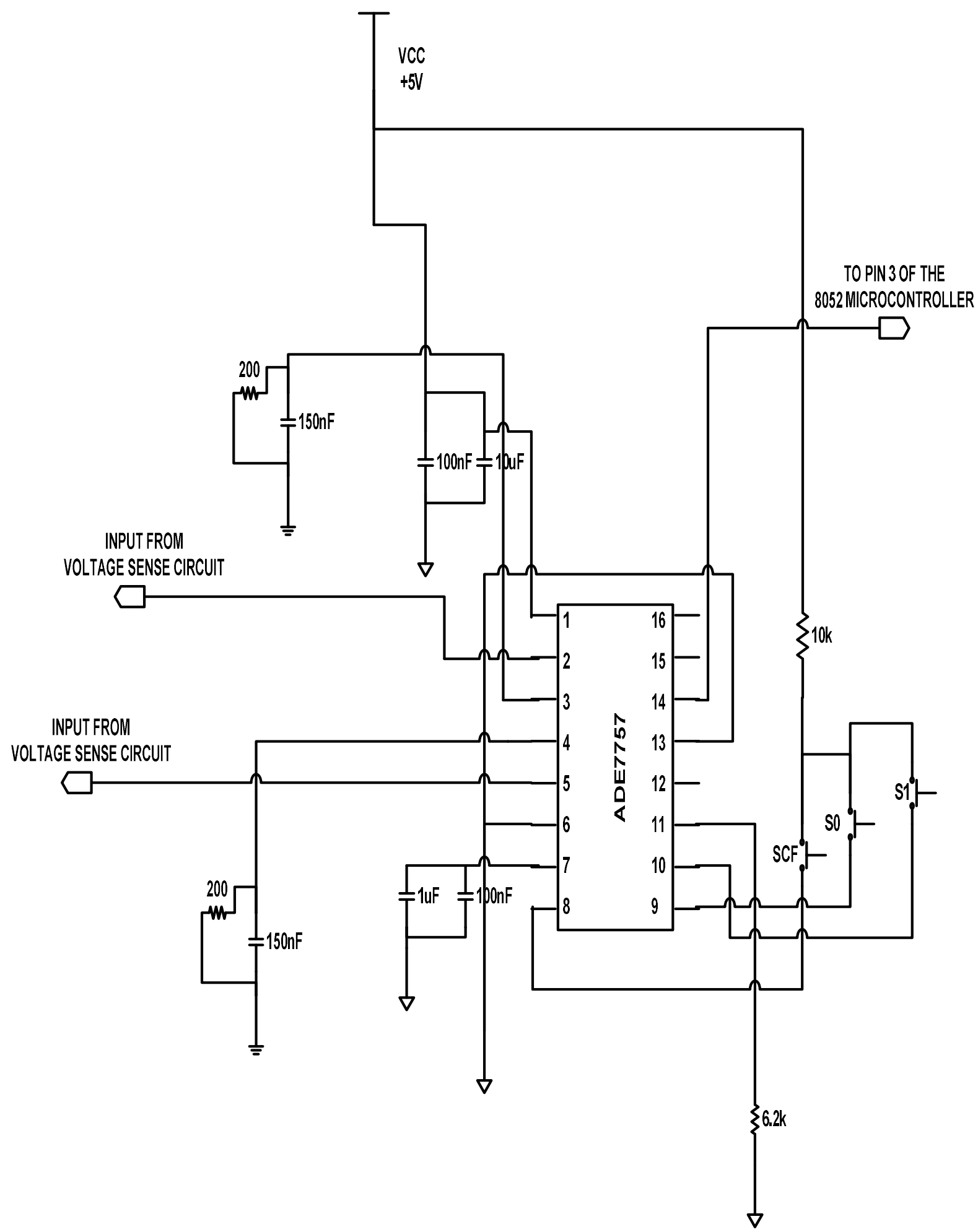

Figure 4.11: Diagram of the ADE7757 connection circuit 
Table 4.1: Calibration Frequency Selection

\begin{tabular}{|l|l|l|l|}
\hline SCF & S1 & S0 & CF Max for AC signals \\
\hline 1 & 0 & 0 & $128 \times$ F1, F2 $=22.4$ \\
\hline 0 & 0 & 0 & $64 \times$ F1, F2 $=11.2$ \\
\hline 1 & 0 & 1 & $64 \times$ F1, F2 $=22.4$ \\
\hline 0 & 0 & 1 & $32 \times$ F1, F2 $=11.2$ \\
\hline 1 & 1 & 0 & $32 \times$ F1, F2 $=22.4$ \\
\hline 0 & 1 & 0 & $16 \times$ F1, F2 $=11.2$ \\
\hline 1 & 1 & 1 & $16 \times$ F1, F2 $=22.4$ \\
\hline 0 & 1 & 1 & $2048 \times$ F1, F2 $=2.867 \mathrm{kHz}$ \\
\hline
\end{tabular}

For this design, we worked with a frequency of $2.867 \mathrm{kHz}$ at the $\mathrm{CF}$ output which is the recommended frequency to be used when interfacing this IC with a microcontroller. Hence, $5 \mathrm{~V}$ is fed to the $\mathrm{S} 1$ and $\mathrm{S} 0$ pins via switches labeled $\mathrm{S} 0$ and $\mathrm{S} 1$ respectively.

Pin 11 RCLKIN: This pin is used to enable the internal oscillator as a clock source to the chip. A precise low temperature $6.2 \mathrm{k} \Omega$ drift resistor is connected from this pin to DGND as specified in the datasheet.

Pin 12 REVP: This logic output will go high when negative power is detected, i.e., when the phase angle between the voltage and current signals is greater than $90^{\circ}$. It is not used in this design.

Pin 13 DGND: This provides the ground reference for the digital circuitry in the ADE7757, i.e., multiplier, filters, and digital-to-frequency converter. It is connected to the digital ground plane of the PCB.

\section{The current transformer}

A current transformer was designed with a voltage transformer of a $240 \mathrm{~V} 500 \mathrm{~mA}$ was also designed to complement the design. The primary winding was rewound to a 3 turn coil using thick copper wire. This was done to accommodate the large current flow in the primary which would be stepped down in the secondary. The secondary of the transformer contains 55 turns. Hence, the transformer has a turn's ratio of $3: 55$.

To obtain the voltage drop across the primary of the transformer, we need to determine the resistance of the primary winding. The resistance of the coil is given by

$$
\begin{aligned}
& \mathrm{R}=\mu \times \mathrm{L} / \mathrm{A} \\
& \text { Where } \mathrm{R}=\text { resistance of copper coil } \\
& \mu=\text { resistivity of copper wire }=0.017 \times 10^{-6} \Omega \mathrm{m} \\
& \mathrm{L}=\text { length of copper coil }=55 \mathrm{~cm}=0.55 \mathrm{~m} \\
& \mathrm{~A}=\text { cross sectional area of copper wire } \\
& \text { Diameter of the wire } \mathrm{D}=1.5 \mathrm{~mm}=0.015 \mathrm{~m} \\
& \text { Hence, } \mathrm{A}=\pi D^{2} / 4 \\
& \begin{array}{l}
=3.14 \times 0.0015^{2} / 4 \\
=1.77 \times 10^{-6}
\end{array}
\end{aligned}
$$


Therefore for a maximum current of $60 \mathrm{~A}$, the maximum input voltage is given by

$\mathrm{V}=\mathrm{IR}$

$=60 \times 5.28 \times 10^{-3}$

$=0.316 \mathrm{~V}$

To obtain the maximum output voltage, we apply the transformation ratio formula as shown below:

$\mathrm{N} 2 / \mathrm{N} 1=\mathrm{V} 2 / \mathrm{V} 1$

Where $\mathrm{N} 2=$ turns ratio $=55 / 3$

$\mathrm{V} 2=$ secondary voltage $=$ ??

$\mathrm{V} 1=$ primary voltage $=0.316 \mathrm{~V}$

Hence, $55 / 3=\mathrm{V} 2 / 0.06$

$\mathrm{V} 2=55 \times 0.316 / 3$

$=5.8 \mathrm{~V}$

\subsection{Design of the Power Supply/Signal Sensing Unit}

This unit comprises of three main sub-units, the voltage sense, current sense and the power supply unit.

\section{Power Supply}

The power supply unit is designed to generate three dc voltages; $+5 \mathrm{~V},+10 \mathrm{~V}$ and $-10 \mathrm{~V}$. The $5 \mathrm{~V}$ power supply is generated as described in the ADE7757 circuit power supply above.

$+10 \mathrm{~V}$ and $-10 \mathrm{~V}$ supply

The LM317 and LM337 voltage regulators were used to produce the required $+10 \mathrm{~V}$ and $-10 \mathrm{~V}$ respectively. The circuit diagram is shown below.

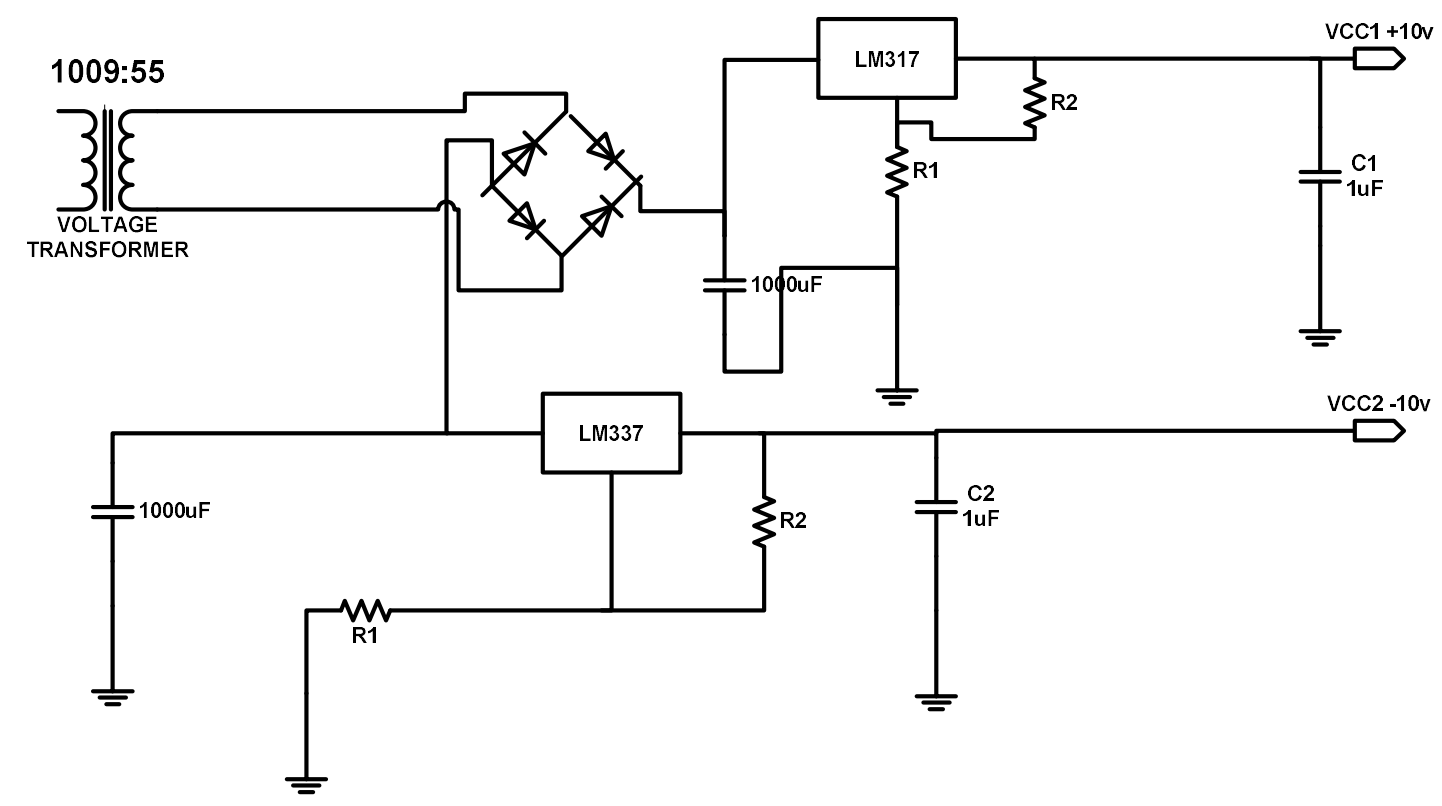

Figure 4.12: Circuit diagram of $+10 \mathrm{v}$ and $-10 \mathrm{v}$ Supply 
A $1000 \mu \mathrm{F}$ capacitor was used to produce the desired filtering of the input signal. The resistor R1 is chosen to give an approximate $10 \mathrm{~V}$ across the ICs. To achieve this, R2 is chosen as $220 \Omega$.

If Vout $=$ required output from voltage regulator $=10 \mathrm{~V}$

The expression for Vout is given by

Vout $=1.25\left(1+\frac{R 1}{R 2}\right)$

$10=1.25\left(1+\frac{R 1}{220}\right)$

$R \mathbf{1}=1.54 K \Omega$

Hence, we use $1.8 \mathrm{~K} \Omega$

The same value of $\mathrm{R} 1$ is used to obtain $-10 \mathrm{~V}$ at the output of the LM337 voltage regulator.

Capacitors C1 and C2 improve the transient response of the output voltage. They are obtained as shown below.

Rout of LM317 $=\frac{\text { Vout }}{I \max }=\frac{10}{1.5}=6.67 \Omega$

An output rise time Tr of $5 \mu$ s was designed. Hence,

$\operatorname{Tr}=$ Rout $\times C 1$

$C 1=\frac{T r}{\text { Rout }}=0.75 \mu F$

Hence, the preferred value of $\mathrm{C} 1$ and $\mathrm{C} 2$ is $1 \mu \mathrm{F}$.

\section{Power Indicator}

The power supply indicator is a Light emitting diode with specifications

- $\quad$ Led current $=10 \mathrm{~mA}$

- $\quad$ Led voltage $=1.8 \mathrm{~V}$

$$
\begin{aligned}
& \text { Resistor } R 1=\frac{V C C-V(\text { led })}{I \text { (led })} \\
& \frac{5-1.8}{10} \times 10^{3} \\
& =320 \Omega
\end{aligned}
$$

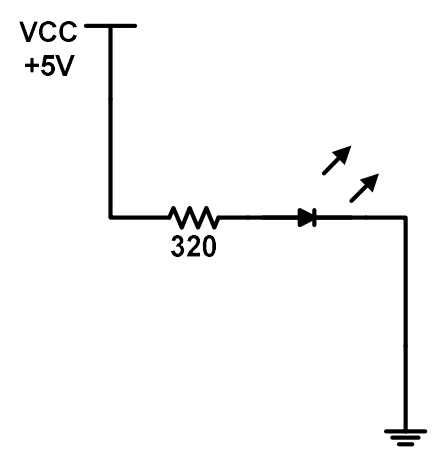




\subsection{Voltage and Current Signal Attenuation Network}

The output voltages of the voltage and current transformers are stepped down to a maximum of $4 \mathrm{~V}$ required by the ADCs by the attenuation network shown below.

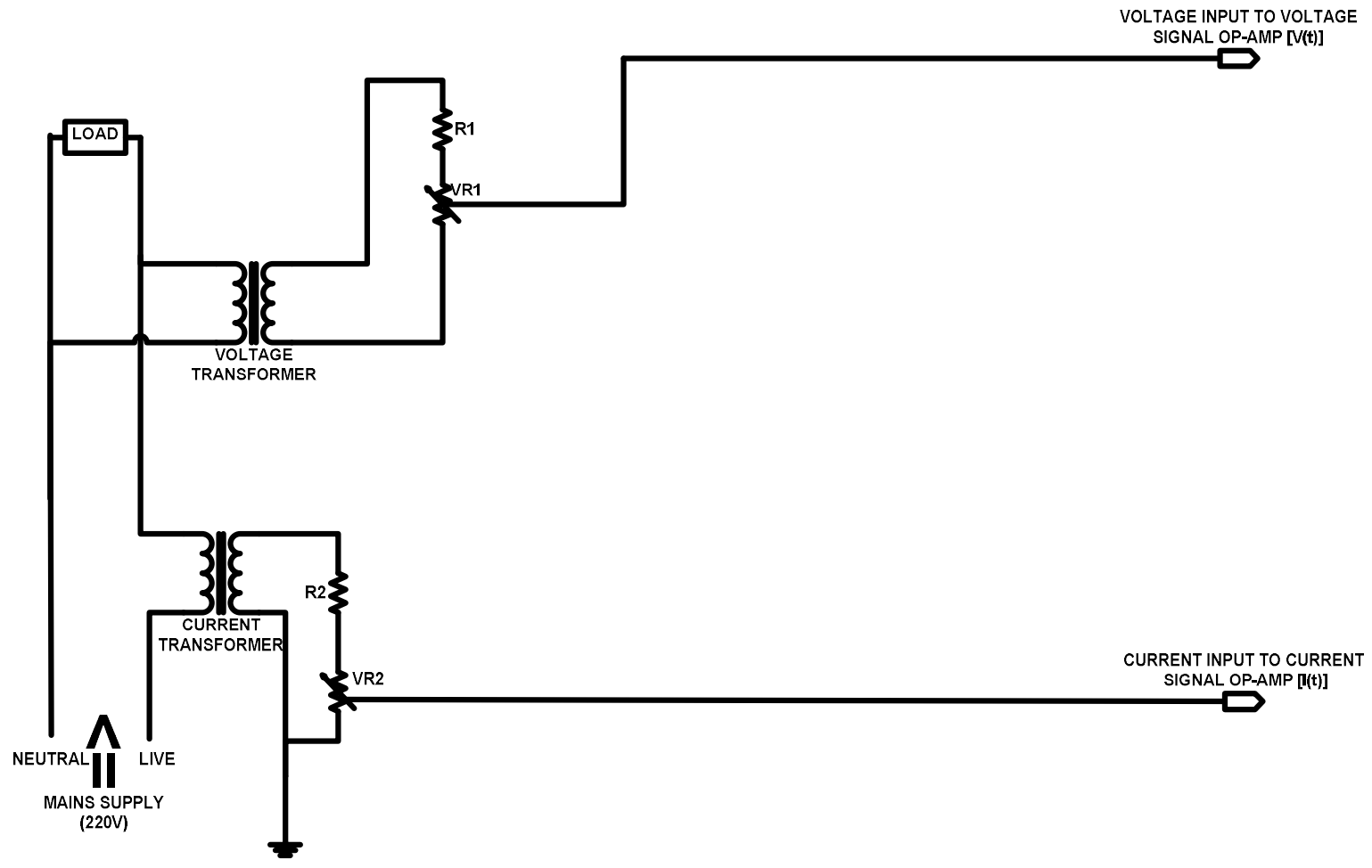

Figure 4.13: Circuit Diagram of the Voltage and Current Signal Attenuation Network

A fixed resistor R1 and a variable resistor VR1 is connected across the voltage transformer. This is done so as to step down the output $12 \mathrm{~V}$ of the transformer to the required $4 \mathrm{~V}$ maximum. A collected voltage across a resistance of $100 \mathrm{~K}$ was carried out. Hence, the value of $\mathrm{R} 1$ can be obtained by applying the voltage divider rule.

$V 2=\frac{(V 1 \times(R 1+50 K)}{(R 1+100 K+50 K)}$

$V 2(R 1+150 K)=V 1 R 1+50 K \times V 1$

$V 2 R 1-V 1 R 1=(50 K \times V 1)-(V 2 \times 150 K)$

$R 1=\frac{50000 \mathrm{~V} 1-150000 \mathrm{~V} 2}{(V 2-V 1)}$

Where $V 1=12 v, V 2=12 v-4 v=8 v$

Then,

$R 1=\frac{(500000 \times 12)-(150000 \times 8)}{(8-12)}$

$R 1=150 K \Omega$ 
Hence, the fixed resistor $\mathrm{R} 1$ is $150 \mathrm{~K} \Omega$ and the variable resistor is a $150 \mathrm{~K}$ variable resistor set to a $100 \mathrm{~K}: 50 \mathrm{~K}$ ratio. For the current signal attenuation network, a fixed resistor $\mathrm{R} 2$ and a $1 \mathrm{~K}$ variable resistor VR2 is connected across the current transformer. This is done so as to step down the output voltage of the transformer to the required $4 \mathrm{~V}$ maximum. The maximum output voltage of the transformer is $6.38 \mathrm{~V}$. We decided to collect the desired $4 \mathrm{~V}$ across a resistance of $700 \Omega$. hence, the value of $\mathrm{R} 2$ can be obtained by applying the voltage divider rule.

$V 2=\frac{(V 1 \times(R 2+300)}{(R 2+300+700)}$

$V 2(R 2+1 K)=V 1 R 2+500 V 1$

$V 2 R 2-V 1 R 2=(300 V 1)-(V 2 \times 1 K)$

$R 2=\frac{300 V 1-1000 V 2}{(V 2-V 1)}$

Where $V 1=6.38 v, \quad V 2=6.38-4=2.38 v$

Then,

$R 2=\frac{(300 \times 6.38)-(1000 \times 2.38)}{(2.38-6.38)}$

$R 2=116.5 \Omega$

Hence we use $\mathrm{R} 2=100 \Omega$ and set VR2 to a 300:700 ratio.

\section{DATA PRESENTATION}

When power consumption falls below certain minimum amount, then a message will be sent to customer mobile phone and when they consumes more than allocated power, the system reset and regulate the power consumed and send message to wireless based monitoring station and some appliances will not be able to draw power and customers will need to shed some load to restore power. Shown in Figure 5.1 and 5.2 Monitoring customers meters (Meter status when balance is zeros and for low balance).

\begin{tabular}{|l|l|l|l|}
\hline \multicolumn{5}{|c|}{ ENERGY MONITORING SYSTEM } \\
\hline \multirow{3}{*}{ HOME } & ENTER RECHARGEAMOUNT & 200 & NAIRA \\
\cline { 2 - 4 } & ONEUNITCOST & 5.00 & NAIRA \\
\hline \multirow{2}{*}{ REALTIME } & RUNNING COUNT & 40 & KWH \\
\cline { 2 - 4 } & TOTALCONSUMPTION & 40 & KWH \\
\hline \multirow{3}{*}{ SINGLEPHASE } & BALANCEUNITS & 0.00 & KWH \\
\cline { 2 - 4 } & BALANCEAMOUNT & 0.00 & NAIRA \\
\hline \multirow{2}{*}{ REPORTS } & METER STATUS & OFF \\
\cline { 2 - 4 } & CLICKHERE FOR RECHARGEAFTER ENTERING RECHARGEAMOUNT \\
\hline DAYS & LOWBALANCERECHARGE IMMEDIATELY \\
\hline
\end{tabular}

Figure 5.1 Monitoring customers meters (Meter status when balance is zeros) 


\begin{tabular}{|c|c|c|c|}
\hline \multicolumn{4}{|c|}{ ENERGY MONITORING SYSTEMI } \\
\hline \multirow[t]{2}{*}{ HOME } & ENTERRECHARGEAMOUNT & 200 & NAIRA \\
\hline & ONEUNITCOST & 5.00 & NAIRA \\
\hline \multirow{2}{*}{ REALTIME } & RUNNING COUNT & 31 & KWH \\
\hline & TOTALCONSUMPTION & 31 & KWH \\
\hline \multirow[t]{2}{*}{ SINGLEPHASE } & BALANCEUNITS & 9.00 & KWH \\
\hline & BALANCEAMOUNT & 45.00 & NAIRA \\
\hline \multirow[t]{2}{*}{ TRENDS } & \multicolumn{2}{|l|}{ METER STATUS } & ON \\
\hline & \multicolumn{3}{|c|}{ CLCKHERE FOR RECHARGEAFTER ENTERING RECHARGEAMOUNT } \\
\hline REPORTS & \multicolumn{3}{|c|}{ LOWBALANCERECHARGEIMMEDIATELY } \\
\hline DAYS & \multicolumn{3}{|c|}{ 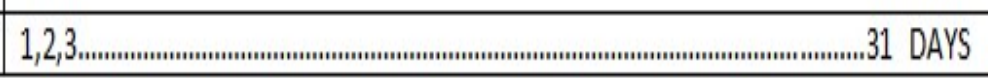 } \\
\hline
\end{tabular}

Figure 5.2 Monitoring customers meters (Meter status when balance is Low)

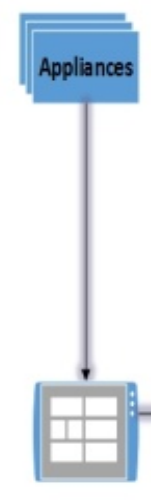

Monitoring System

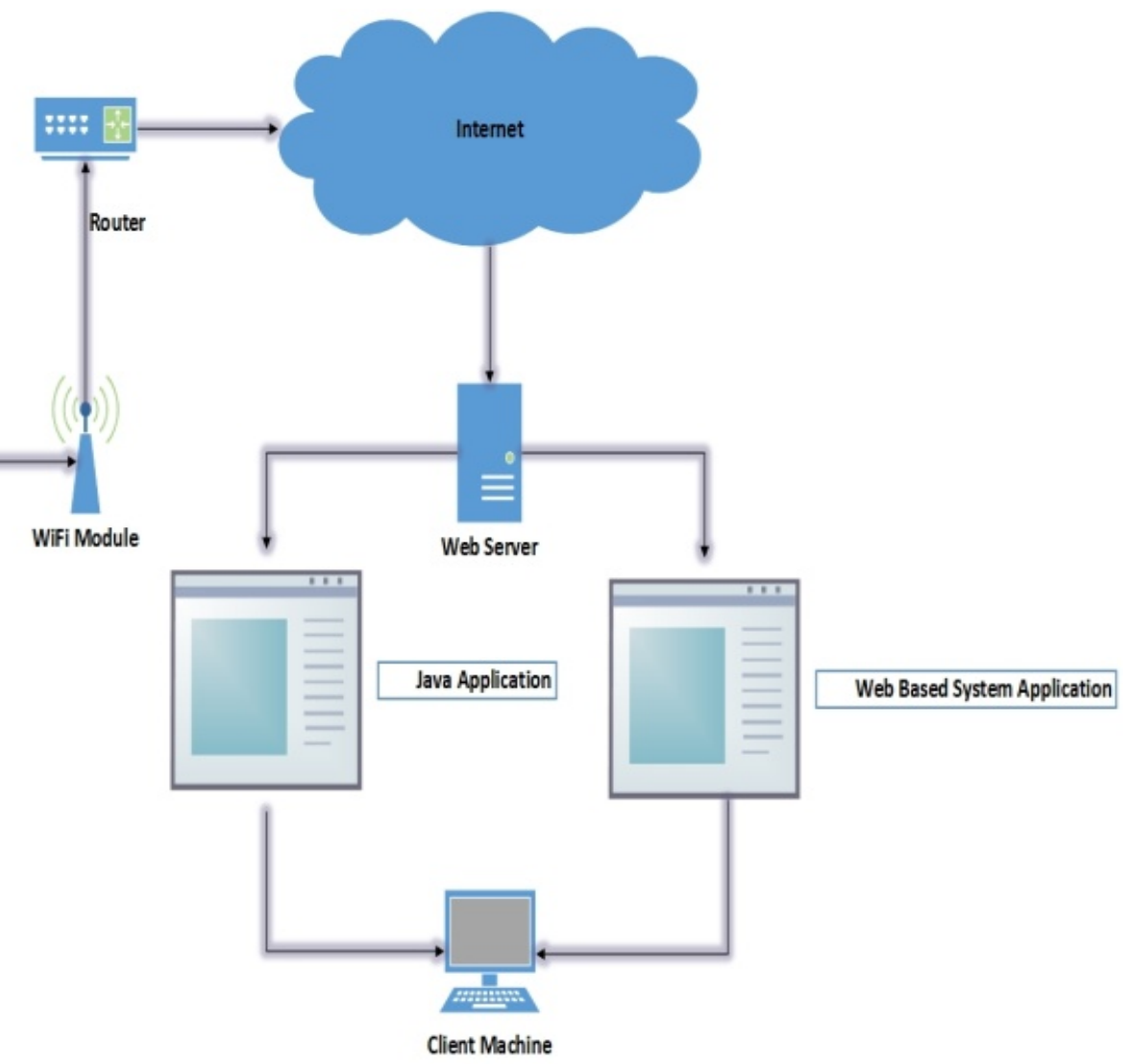

Figure 5.3: Setup of the Home Energy Planner 


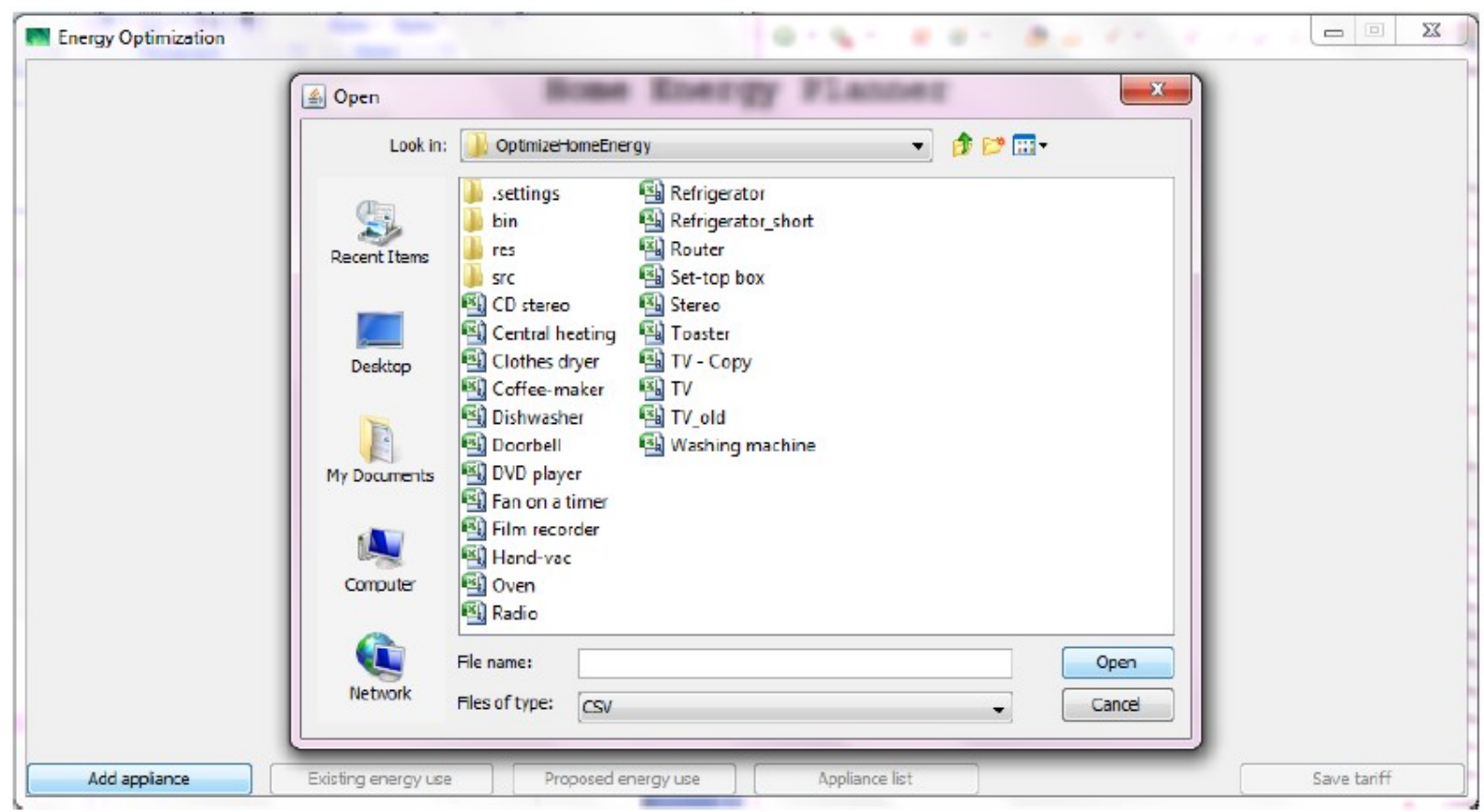

Figure 5.4: Test results showing End-user able to select appliances to upload.

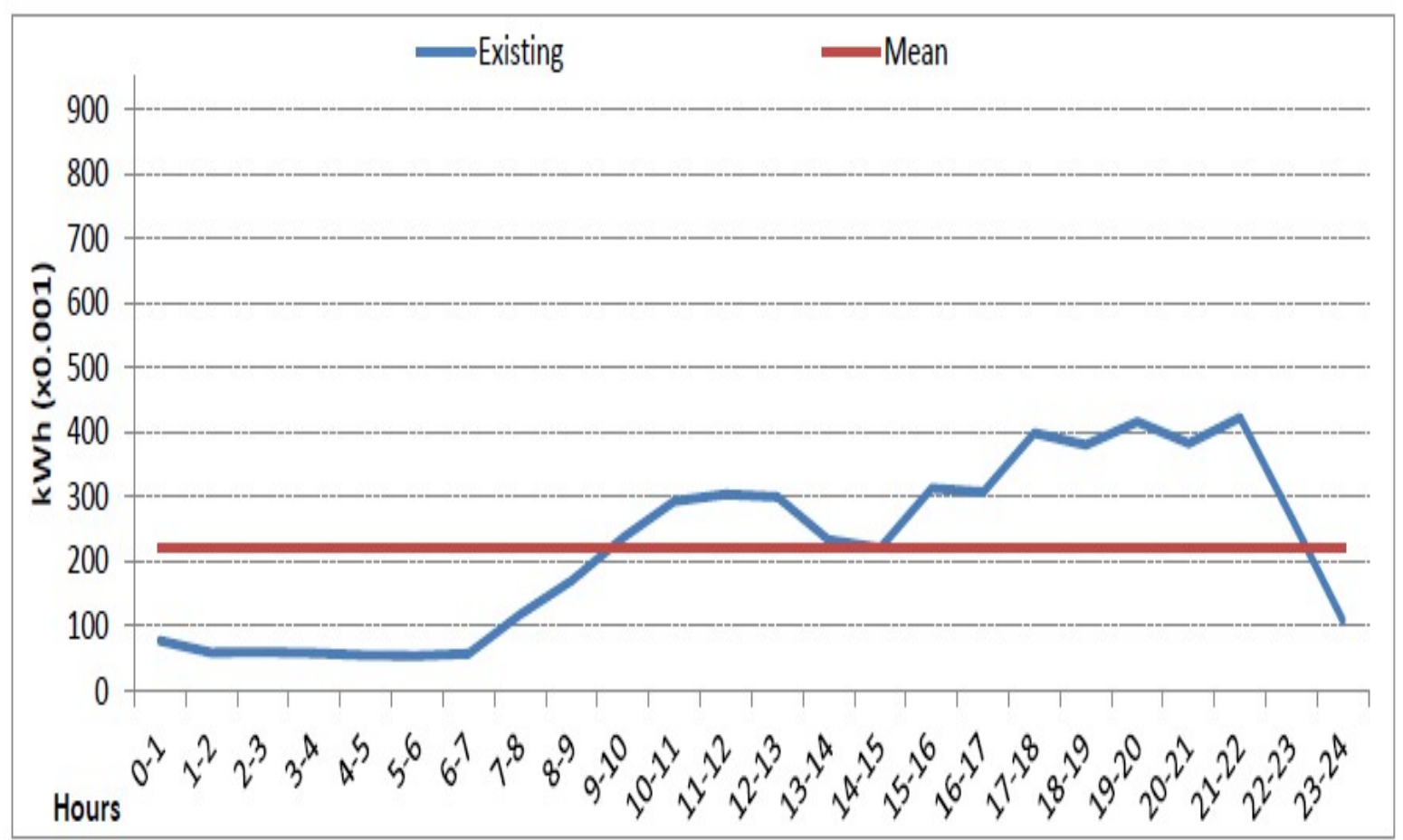

Figure 5.5a: Average electricity consumption of the existing system for one day using 8 Months data. 


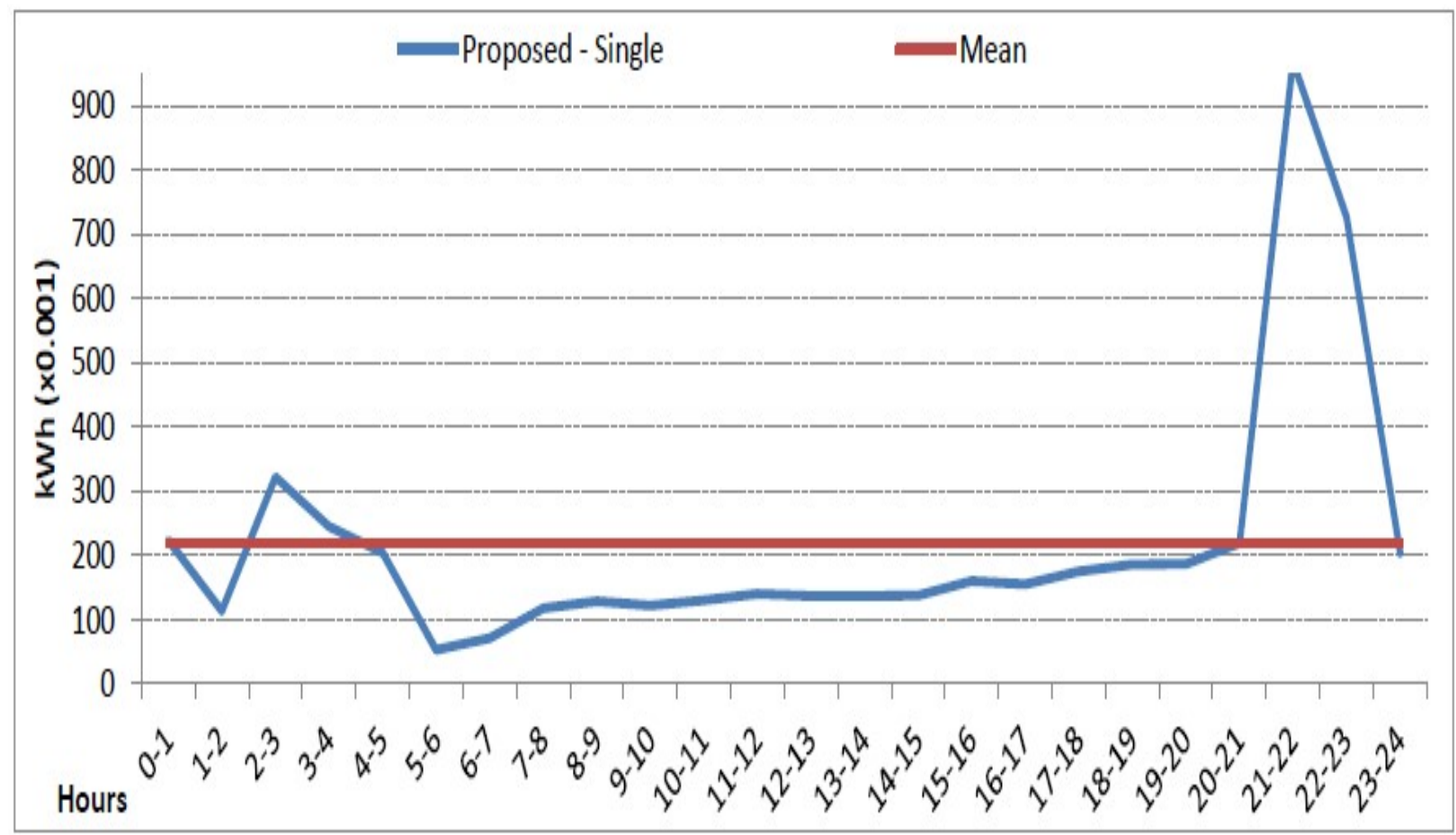

Figure 5.5b: Average electricity consumption of the Single tariff system for one day using 8 Months data.

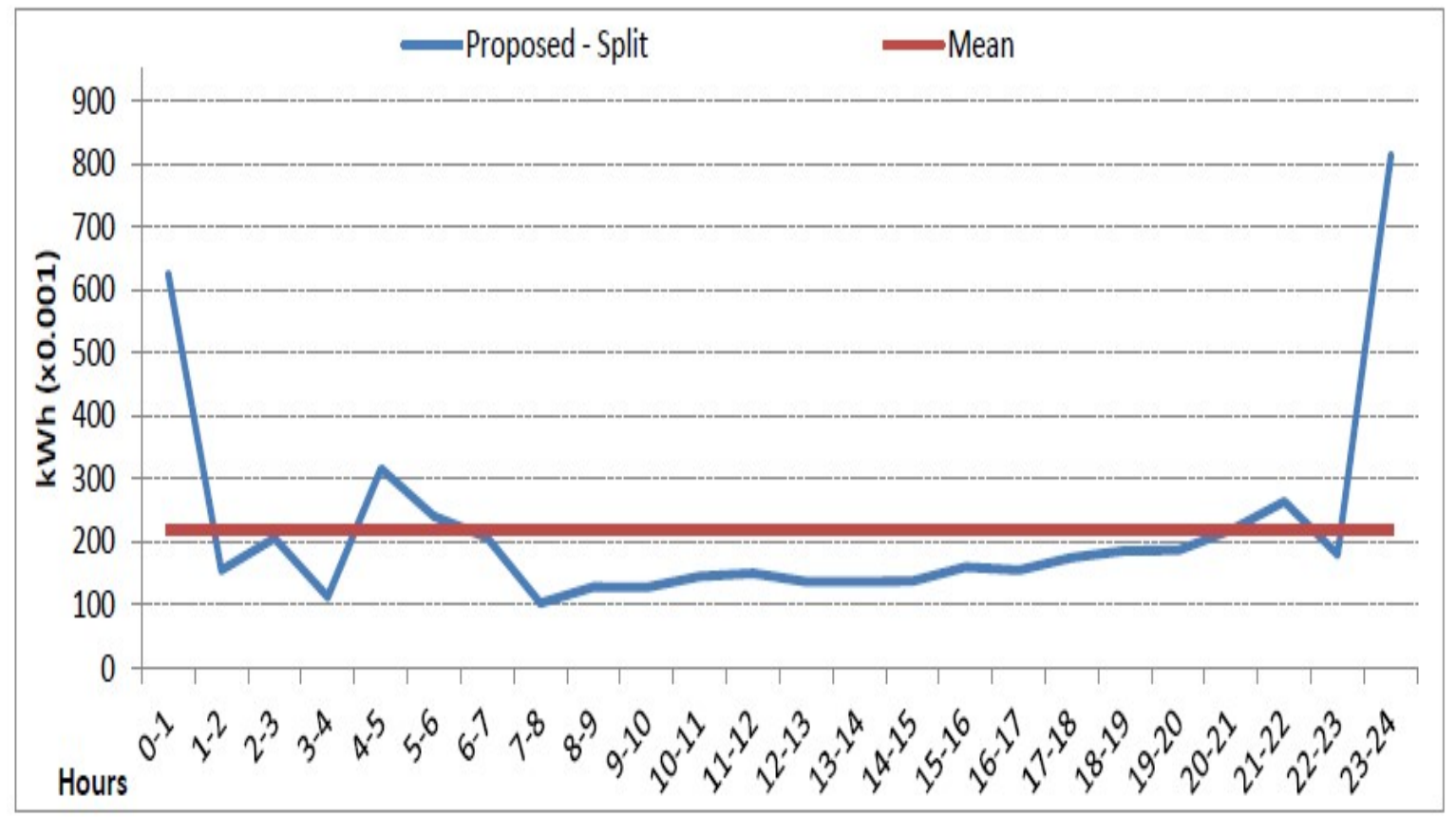

Figure 5.5c: Average electricity consumption of the split tariff system for one day using 8 Months data. 


\section{DISCUSSION OF FINDINGS}

The expected outcome of this research is that it will enable end-users being able to manage their electricity consumption, determine the timing schedule of appliances either flexible or strict or both (see figure 5.3), with the automated metering system, Centralized wireless based monitoring system and tamper proof which also includes inbuilt fraud and fault detection, the utility company will be able to eliminate the possibility of electricity theft, non-payment of electricity bills and save huge amount of money for the distribution company.

The preliminary findings that may require further investigation are as follows:

i. Most wireless based system were not design with inbuilt fault detection and fraud detection same time.

ii. Most automated metering system was not incorporated with flexible home energy planner.

iii. It is very rare to find centralized monitoring system be used for even load shedding and load dependent.

\section{CONCLUDING REMARKS}

The proposed system solved the problem of power management and monitoring the energy usage in different prepaid meters of various customers. The Live comparison of energy usage monitored on a centralized wireless based system. With the help of Home Energy planner, end-users able to determine the timing schedules to turn appliances on and off automatically and reduce waste. It also helped customers make payment easily with the help of web-based system. This system will eliminate the possibility of non-payment of electricity bills by customers, electricity theft and economically beneficial.

\section{CONTRIBUTIONS TO KNOWLEDGE}

The major contributions to the body of knowledge from the research are the development of a centralized wireless based metering monitoring system capable of automatic billing system, load dependent and load shedding. The system can also be adopted as an home energy planner.

\section{REFERENCES}

1. Olugbenga T K, Abdul-Ganiyu A. Jumah and Philip D.A " The Current and Future Challenge of Electricity market in Nigeria in the face of deregulation Process" African Journal of Engineering Research Volume 1, Issue 2, March 2013. Pp.33-39.

2. Orukpe P.E and Agbontaen F.O, Prepaid meter in Nigeria: The story so Far and the way Forward, Advanced materials Research Vol.824 (2013) Pp 114-119 (C) (2013) Trans Tech Publications, Switzerland doi:10.4028/www.scientific.net/AMR.824.114

3. Apeh S. T. and Mokogwu C. N "Developed a home power management system" Nigeria Journal of Technological Researrch- Volume 8, Issue 2 (2013). Pp. 30-34

4. Sepala, A "the estimation and simulation of electricity Proceeding of the 14 th power system computation conference PSCC. Dresden, 19-23, Pp 238-244, 2014.

5. Raghavendra. R et al, “ No power struggles: Coordinated Multi-level power management for data centre, Hewlett Packard Technical Report, HPL-TR-2011194, December, 2011.

6. Mousami .S. Vanjale, Asmita Deshpande, Krunal Pawale, Pooja Bhagwat (2014).

Automatic Security System Based on Wireless Sensor Network and GSM Technology. International Journal of Engineering Research and Technology (IJERT). ISSN: 2278-0181. Volume 3 issue 4. Released April 2014. 
7. Mehek Potnis, Ayesha Chimnani, Visha Chawla, Amit Hatekar (2015). Home security system using GSM Modem. International Journal of Engineering Research and application (IJERA). ISSN: 2248-9622, Vol. 5, Issue 4, (Part-6). Released April 2015.

8. Malaysia External Trade Development Corporation (MATRADE), Electrical and Electronic Directory 2011-2013, (Article) 2013.

9. Merlin Sharmila, S.Savitha Raj (2014) , 'A Smart Distribution Automation using Supervisory Control and Data Acquisition with Advanced Metering infrastructure and GPRS Technology', International Journal of Engineering Research and General Science Volume 2, Issue 5, ISSN 2091-2730.

10. Rodrigo P et al "Monitoring and Controlling Services for Electrical Distribution Systems Based on the IEC 61850 Standard", Energy and Power Engineering, 299-309.NXP builds smart washing machine with NFC and fabric detection. Pocket-lint. [Online] Pocket-lint ltd, March 12, 2012. ( March 24, 2013).

11. Cabral et al, "Fraud detection in electrical energy consumers using rough sets," in Proc. IEEEInt. Conf. Systems, Man and Cybernetics, Oct. 10-13, 2004, vol. 4, pp.3625-3629.

12. Bilbao et al,"Determination of energy losses," in Proc. 16th Int. Conf. Exhibition on Electricity Distribution (CIRED) 2001, Amsterdam, The Netherlands,vol. 5, 4 pp. vol. 5

13. Filho J. R, Gontijo E.M, Delaiba A.C, Mazina E, Cabral J.E, and Pinto J.O.P, "Fraud identification in electricity company customers using decision trees," in Proc. 2004 IEEE Int. Conf. Systems, Man andCybernetics, Oct. 10-13, 2004, vol. 4, pp. 3730-3734.

14. Zhao et al, "A data mining based NTL analysis method," in Proc. IEEE Power Eng. Soc. General Meeting, Tampa, FL, Jun. 24-28, 2007, pp. 1-8.

15. Galvan et al, "System for detection of abnormalities and fraud in customer consumption," in Proc. 12th Conf. Electric Power Supply Industry, Pattaya,Thailand, Nov. 1998.

16. Nizar A. N, Dong Z. Y, and Zhao J.H, "Load profiling and data mining techniques in electricity deregulated market," presented at the IEEE Power Eng. Soc. General Meeting, Montreal, QC, Canada, Jun.18-22, 2006, paper 06GM0828.

17. A. H. Nizar, Z. Y. Dong, M. Jalaluddin, and M. J. Raffles, "Load profiling method in detecting non-technical loss activities in a power utility," in Proc. IEEE 1st Int. Power and Energy Conf., Putrajaya, Malaysia, Nov. 28-29, 2006, pp. 82-87.

18. D. Gerbec, S. Gasperic, I. Smon, and F. Gubina, Allocation of the load profiles to consumers using probabilistic neural networks," IEEE Trans. Power Syst., vol. 20, no. 2, pp. 548-555, May 2005. 